\title{
The Influence of Network Economy on the High- quality Development of China's Economy
}

\author{
Hongzhi TIAN and Qiuli WANG* \\ Northwest University, Xi'an, China; nwuthz@nwu.edu.cn; wangqiuli0925@163.com \\ * Corresponding author: wangqiuli0925@163.com
}

\begin{abstract}
What impact does the Internet economy have on the high-quality development of China's economy? This paper finds that, first, the quality of economic development in most provinces and regions in China has been significantly improved in recent years, while the high-quality development level of Beijing, Shanghai and Guangdong, where the network economy is better developed, is mediocre, reflecting the need to further deepen the synergy between the network economy and high-quality development. Secondly, both the network economy and the high-quality economic development can realize their own development inertia. Third, the effect of high-quality economic development on network economy takes a long time. It is negative utility from the first year after the occurrence of high-quality pulse, and gradually turns to positive utility from the second year. Fourth, the development of the network economy significantly contributes to the high-quality development of our economy with positive effects in both the South and the North, and shows a long-term boost that lasts for four years.
\end{abstract}

Keywords: network economy; quality development; panel vector autoregressive models

JEL Classification: F49; F12

\section{Introduction}

With its fast information dissemination, massive information capacity and interactive information experience, the network has powerfully shortened the process of creating and accepting new knowledge and realized the rapid popularization of new technologies and new business models. To promote high-quality economic development, it is necessary to focus on meeting people's needs for a better life, while focusing on cracking the unbalanced and insufficient development contradictions and problems. The continuous growth of new dynamics of economic development and the emergence of new industries, new business models and new business models have further enhanced China's economic vitality and strongly promoted China's economic development towards high quality. Among the indexes of new dynamics of economic development, the network economy has the highest increase and the largest contribution, so it is of practical significance to study the impact of the development of the network economy on the high quality of China's economy in this context. Through this study, we examine the new dynamics of the network economy and use it to determine whether it is a new driving force for sustainable and high-quality economic development in China. 


\section{Literature Review}

As China's economy moves from quantitative to qualitative growth, high-quality economic development approaches and goals have become an urgent development task for China today. Ren (2015) has recognized the economic consequences and social consequences of quantitative economic growth. The economic consequences include the drawbacks of dense population, urban congestion, environmental pollution, resource consumption, and declining welfare. In terms of social consequences, overemphasis on quantity-based growth leads people to fall into the loop of growth for the sake of growth. Specifically, economic high quality is innovative, coordinated, green, open and shared development, and is a high-level state of economic development approach, structure and dynamics (Jin, 2018). Shi (2018) believes that high-quality economic development should be measured in three dimensions, including the fundamental side of development, the ecological outcome side and the social outcome side. Ren (2018) pointed out that indicators of high-quality economic development should include economic development, urban infrastructure, education and retirement, ecological environment, and healthcare. Li (2019) constructs indicators of China's highquality economic development in the new era from five dimensions: innovation, coordination, green, openness, and sharing.

Through literature combing, this paper has so far studied the development of network economy and economic high-quality development of the literature is relatively small, most of the literature only from the theoretical perspective to analyze the impact of network economy on China's economy and does not involve quantitative empirical research. In this paper, based on the existing studies, we take the panel data of 30 Chinese provinces and cities from 2013-2017 as the analysis sample, calculate China's network economy development indicators firstly through the entropy value method, then measure China's economic highquality development indicators. And use the panel vector autoregression (PVAR) model to study the impact of network economy development on economic high-quality development, with a view to providing policy implications for China's network economy development and the PVAR model is then used to study the impact of network economy development on highquality economic development, with a view to providing policy implications for China's network economy development and high-quality economic development.

\section{Methodology}

\subsection{Construction of the Indicator System}

\subsubsection{Network Economy Development Evaluation Index System}

In this paper, we refer to the study of $\mathrm{Li}$ (2018) and combine the actual situation in China to construct the network economy development evaluation index system from the following five aspects, which are shown in Table 1. 
Table 1. Network economy development evaluation index system

\begin{tabular}{|c|c|c|c|}
\hline Target layer & Criteria layer & Indicator layer & $+/-$ \\
\hline \multirow{13}{*}{$\begin{array}{c}\text { Network } \\
\text { economy } \\
\text { development } \\
\text { level }\end{array}$} & \multirow{3}{*}{$\begin{array}{l}\text { Network economy support } \\
\text { level }\end{array}$} & $\begin{array}{c}\text { Transportation, post and telecommunications } \\
\text { output as a proportion of GDP }\end{array}$ & + \\
\hline & & $\begin{array}{c}\text { Research and development expenditure as a } \\
\text { proportion of GDP }\end{array}$ & + \\
\hline & & Investment in education as a proportion of GDP & + \\
\hline & \multirow{2}{*}{$\begin{array}{c}\text { Network Infrastructure } \\
\text { Construction }\end{array}$} & Long distance fiber optic cable line length & + \\
\hline & & Cell phones per 100 people & + \\
\hline & \multirow{4}{*}{$\begin{array}{l}\text { Network development and } \\
\text { application level }\end{array}$} & Network Number & + \\
\hline & & Number of Domains & + \\
\hline & & $\begin{array}{c}\text { Number of people online as a percentage of } \\
\text { total population }\end{array}$ & + \\
\hline & & Total telecom services per capita & + \\
\hline & \multirow{3}{*}{$\begin{array}{l}\text { Network Economy Talent } \\
\text { Resources }\end{array}$} & Number of college students per 10,000 people & + \\
\hline & & $\begin{array}{l}\text { Number of scientific and technical personnel } \\
\text { per } 10,000 \text { people }\end{array}$ & + \\
\hline & & $\begin{array}{l}\text { Proportion of total employees in transportation, } \\
\text { post and telecommunications }\end{array}$ & + \\
\hline & $\begin{array}{c}\text { Network Economy } \\
\text { Development Results }\end{array}$ & E-commerce sales & + \\
\hline
\end{tabular}

\subsubsection{Network Economy Development Evaluation Index System}

In this paper, the construction of economic quality development index system mainly focuses on the five major development concepts of "innovation, coordination, green, openness and sharing", and the evaluation index system of economic quality development is constructed by referring to the latest literature of $\mathrm{Wu}$ and Liang (2020), as shown in Table 2.

Table 2. Economic quality development evaluation index system

\begin{tabular}{|c|c|c|c|}
\hline Target layer & Criteria layer & Indicator layer & $+/-$ \\
\hline \multirow{15}{*}{$\begin{array}{c}\text { Degree of high- } \\
\text { quality } \\
\text { economic } \\
\text { development }\end{array}$} & \multirow{4}{*}{ Innovative Development } & $\begin{array}{l}\text { Scientific research, technical services and other } \\
\text { fixed assets investment ratio }\end{array}$ & + \\
\hline & & Capital productivity & + \\
\hline & & $\begin{array}{c}\text { Share of education expenditure in total fiscal } \\
\text { expenditure }\end{array}$ & + \\
\hline & & Value added of tertiary industry as a share of GDP & + \\
\hline & \multirow{2}{*}{$\begin{array}{l}\text { Coordinated } \\
\text { Development }\end{array}$} & Urban-rural income ratio & - \\
\hline & & Consumer price index (previous year=100) & - \\
\hline & \multirow[b]{3}{*}{ Green Development } & SO2 emissions per unit of regional output & - \\
\hline & & Emission of wastewater per unit area output & - \\
\hline & & $\begin{array}{l}\text { Share of environmental protection expenditure in } \\
\text { fiscal expenditure } \\
\text { Ratio of total import and export to GDP }\end{array}$ & + \\
\hline & \multirow{3}{*}{ Open Development } & Ratio of total import and export to GDP & + \\
\hline & & Ratio of real foreign direct investment to GDP & + \\
\hline & & Reception of international tourists & + \\
\hline & \multirow{3}{*}{ Shared Development } & Per capita GDP & + \\
\hline & & $\begin{array}{l}\text { Number of beds in medical institutions per } 10,000 \\
\text { people }\end{array}$ & + \\
\hline & & $\begin{array}{l}\text { Share of social security and employment } \\
\text { expenditure in total fiscal expenditure }\end{array}$ & + \\
\hline
\end{tabular}




\subsection{Measurements}

\subsubsection{Entropy Method}

Based on the evaluation index system of network economic development and highquality economic development constructed in the previous paper, this paper adopts the entropy value method to quantitatively analyze the network economic development and high-quality economic development in China. The specific calculation method is as follows.

Step 1: Standardization of the indicators. With $r$ years, $n$ provinces and cities, and $m$ indicators, $x_{i j t}$ is the value of the $j$ th secondary indicator of province $i$ in year $t$. Since different indicators have different levels and units, they need to be standardized to obtain the standardized secondary indicators $r_{i j t}$. For the positive indicators, the transformation formula is as follows.

$$
r_{i j t}=\frac{x_{i j t}-\min \left(x_{j}\right)}{\max \left(x_{j}\right)-\min \left(x_{j}\right)}
$$

For the inverse indicator, the transformation equation is as follows.

$$
r_{i j t}=\frac{\max \left(x_{j}\right)-x_{i j t}}{\max \left(x_{j}\right)-\min \left(x_{j}\right)}
$$

Step 2: Calculate the characteristic weight of the indicator $f_{i j t}$.

$$
f_{i j t}=\frac{r_{i j t}}{\sum_{t=i}^{r} \sum_{i=1}^{n} r_{i j t}}
$$

Step 3: Calculate the information entropy $e_{j}$ and its redundancy $d_{j}$.

$$
\begin{gathered}
e_{j}=\frac{1}{\ln r n} \sum_{t=1}^{r} \sum_{i=1}^{n} f_{i j t} \ln \left(f_{i j t}\right) \\
d_{j}=1-e_{j}
\end{gathered}
$$

Step 4: Determine the weight of the $j$ th secondary indicator $w_{j}$.

$$
w_{j}=\frac{d_{j}}{\sum_{j=1}^{m} d_{j}}
$$

\subsubsection{Panel Vector Autoregressive Model}

In order to further analyze the interaction between network economy development and high-quality economic development, this paper establishes a panel vector autoregressive (PVAR) model and performs generalized moment estimation (GMM) on the parameters of the model, and then uses impulse responses to display the dynamic relationship between the two more intuitively. Among them, the specific structure of the PVAR model is as follows.

$$
Y_{i t}=\theta_{0}+\sum_{j=1}^{k} \theta_{j} Y_{i t-j}+\alpha_{i}+\beta_{t}+u_{i t}
$$

where: $Y$ denotes the binary column vector containing the network economic development and the high-quality economic development; $\theta_{0}$ denotes the vector of intercept terms; $\theta_{j}$ 
denotes the lag $j$-order matrix; $\alpha_{i}, \beta_{t}$ denote individual effects and time effects, respectively; $u$ denotes the random error vector.

\section{Results}

\subsection{Comprehensive Evaluation of Network Economic Development and High-quality Economic} Development

Based on the entropy value method, the level of network economic development and high-quality economic development of 30 provinces and cities are calculated and shown in Table 3 and Table 4 below.

Table 3. Network economic development measurement results by provinces and cities from 2013-2017

\begin{tabular}{|c|c|c|c|c|c|c|}
\hline Region & 2013 & 2014 & 2015 & 2016 & 2017 & Average \\
\hline Beijing & 0.1139 & 0.1323 & 0.1953 & 0.1882 & 0.2047 & 0.1669 \\
\hline Tianjin & 0.0273 & 0.0274 & 0.0434 & 0.0369 & 0.0389 & 0.0348 \\
\hline Hebei & 0.0351 & 0.0431 & 0.0739 & 0.0507 & 0.0596 & 0.0525 \\
\hline Shanxi & 0.0244 & 0.0293 & 0.0493 & 0.0276 & 0.0341 & 0.0329 \\
\hline Inner Mongolia & 0.0162 & 0.0181 & 0.0353 & 0.0255 & 0.0270 & 0.0244 \\
\hline Liaoning & 0.0360 & 0.0392 & 0.0649 & 0.0420 & 0.0497 & 0.0464 \\
\hline Jilin & 0.0225 & 0.0196 & 0.0321 & 0.0246 & 0.0383 & 0.0274 \\
\hline Heilongjiang & 0.0348 & 0.0356 & 0.0498 & 0.0338 & 0.0491 & 0.0406 \\
\hline Shanghai & 0.0845 & 0.0966 & 0.1391 & 0.1138 & 0.1431 & 0.1154 \\
\hline Jiangsu & 0.0695 & 0.0731 & 0.1395 & 0.0871 & 0.0963 & 0.0931 \\
\hline Zhejiang & 0.0630 & 0.0657 & 0.1424 & 0.1070 & 0.1035 & 0.0963 \\
\hline Anhui & 0.0372 & 0.0401 & 0.0686 & 0.0702 & 0.0906 & 0.0613 \\
\hline Fujian & 0.0480 & 0.0515 & 0.0817 & 0.1062 & 0.1539 & 0.0883 \\
\hline Jiangxi & 0.0267 & 0.0250 & 0.0503 & 0.0444 & 0.0519 & 0.0396 \\
\hline Shandong & 0.1003 & 0.0835 & 0.1103 & 0.1114 & 0.1272 & 0.1065 \\
\hline Henan & 0.0543 & 0.0504 & 0.0833 & 0.0798 & 0.0968 & 0.0729 \\
\hline Hubei & 0.0416 & 0.0475 & 0.0718 & 0.0638 & 0.0720 & 0.0593 \\
\hline Hunan & 0.0343 & 0.0369 & 0.0617 & 0.0600 & 0.0650 & 0.0515 \\
\hline Guangdong & 0.1486 & 0.1622 & 0.2098 & 0.2083 & 0.2385 & 0.1935 \\
\hline Guangxi & 0.0302 & 0.0386 & 0.0449 & 0.0444 & 0.0579 & 0.0432 \\
\hline Hainan & 0.0987 & 0.0340 & 0.0591 & 0.0354 & 0.0608 & 0.0576 \\
\hline Chongqing & 0.0329 & 0.0454 & 0.0429 & 0.0446 & 0.0442 & 0.0420 \\
\hline Sichuan & 0.0515 & 0.0640 & 0.0731 & 0.0790 & 0.1671 & 0.0869 \\
\hline Guizhou & 0.0381 & 0.0407 & 0.0533 & 0.0569 & 0.0487 & 0.0476 \\
\hline Yunnan & 0.0491 & 0.0432 & 0.0430 & 0.0481 & 0.1269 & 0.0621 \\
\hline Shanxi & 0.0331 & 0.0487 & 0.0414 & 0.0462 & 0.1030 & 0.0545 \\
\hline Gansu & 0.0206 & 0.0310 & 0.0662 & 0.0437 & 0.0735 & 0.0470 \\
\hline Qinghai & 0.0389 & 0.0230 & 0.0494 & 0.1392 & 0.0828 & 0.0667 \\
\hline Ningxia & 0.0377 & 0.0354 & 0.0191 & 0.0398 & 0.1301 & 0.0524 \\
\hline Xinjiang & 0.0308 & 0.0349 & 0.0324 & 0.0281 & 0.0550 & 0.0363 \\
\hline National average & 0.0493 & 0.0505 & 0.0742 & 0.0696 & 0.0897 & - \\
\hline
\end{tabular}

As can be seen from Table 3, the development of China's network economy has the following characteristics: first, horizontally, the higher level of network economy development in economically developed and southern provinces and regions, among which Guangdong has the highest level of network economy development and has maintained an absolute leading position, which shows that a good economic foundation can promote faster 
development of the network economy. And Tianjin, Hebei, northeast three provinces, Inner Mongolia, Shanxi, Jiangxi, Hunan, Guangxi, Chongqing, Guizhou, Gansu, Xinjiang and other places of network economy development is relatively slow. Second, vertically, the provinces and regions with the fastest growing network economy level are concentrated in Zhejiang, Fujian, Hainan, Sichuan and Shanxi, showing good development momentum. Among them, Zhejiang made the fastest progress in 2015 and 2016, Fujian, Sichuan, Yunnan, Shanxi and Ningxia made the greatest progress in 2017, while Qinghai made significant progress in 2016. Thirdly, for the national average level of network economy development, the continuous development hand was maintained in 2014 and 2015, and although the development strength dropped in 2016, it immediately rebounded strongly in 2017, and the national average reached 0.0897, much higher than the level in 2015. It can be seen that the overall momentum of the development of the network economy in China is good, and the development in areas with high economic level and economic vitality is even better.

Table 4. Economic quality development measurement results by provinces and cities from 2013-2017

\begin{tabular}{|c|c|c|c|c|c|c|}
\hline Region & 2013 & 2014 & 2015 & 2016 & 2017 & Average \\
\hline Beijing & 0.4566 & 0.4928 & 0.5173 & 0.5521 & 0.5177 & 0.5073 \\
\hline Tianjin & 0.6818 & 0.6859 & 0.7019 & 0.7092 & 0.7419 & 0.7042 \\
\hline Hebei & 0.6723 & 0.6526 & 0.6743 & 0.7061 & 0.7083 & 0.6827 \\
\hline Shanxi & 0.5955 & 0.6519 & 0.5989 & 0.6620 & 0.6265 & 0.6270 \\
\hline Inner Mongolia & 0.6576 & 0.6337 & 0.6201 & 0.6189 & 0.6099 & 0.6280 \\
\hline Liaoning & 0.5395 & 0.4951 & 0.5376 & 0.5648 & 0.5850 & 0.5444 \\
\hline Jilin & 0.7364 & 0.7207 & 0.7118 & 0.7338 & 0.7113 & 0.7228 \\
\hline Heilongjiang & 0.6452 & 0.6480 & 0.6350 & 0.6288 & 0.6905 & 0.6495 \\
\hline Shanghai & 0.5083 & 0.5014 & 0.5582 & 0.5773 & 0.5933 & 0.5477 \\
\hline Jiangsu & 0.5813 & 0.5647 & 0.9660 & 0.6098 & 0.6054 & 0.6654 \\
\hline Zhejiang & 0.6216 & 0.6535 & 0.6706 & 0.7083 & 0.7298 & 0.6768 \\
\hline Anhui & 0.7180 & 0.6956 & 0.7187 & 0.7458 & 0.7803 & 0.7317 \\
\hline Fujian & 0.7182 & 0.6769 & 0.7074 & 0.7360 & 0.7549 & 0.7187 \\
\hline Jiangxi & 0.7466 & 0.7195 & 0.7366 & 0.7542 & 0.7716 & 0.7457 \\
\hline Shandong & 0.6065 & 0.5850 & 0.5978 & 0.6178 & 0.6223 & 0.6059 \\
\hline Henan & 0.6665 & 0.6387 & 0.6475 & 0.6865 & 0.7069 & 0.6692 \\
\hline Hubei & 0.6778 & 0.6267 & 0.6568 & 0.6847 & 0.7109 & 0.6714 \\
\hline Hunan & 0.6405 & 0.5880 & 0.6286 & 0.6477 & 0.6909 & 0.6392 \\
\hline Guangdong & 0.5942 & 0.5992 & 0.6181 & 0.6353 & 0.6544 & 0.6203 \\
\hline Guangxi & 0.7691 & 0.7260 & 0.7049 & 0.7218 & 0.7382 & 0.7320 \\
\hline Hainan & 0.8828 & 0.8861 & 0.8731 & 0.9237 & 0.9452 & 0.9022 \\
\hline Chongqing & 0.6291 & 0.5722 & 0.5817 & 0.6118 & 0.6292 & 0.6048 \\
\hline Sichuan & 0.5915 & 0.5783 & 0.5989 & 0.6283 & 0.6464 & 0.6087 \\
\hline Guizhou & 0.6438 & 0.6302 & 0.6539 & 0.6443 & 0.6363 & 0.6417 \\
\hline Yunnan & 0.7064 & 0.6996 & 0.6912 & 0.7432 & 0.7141 & 0.7109 \\
\hline Shanxi & 0.5960 & 0.5812 & 0.5917 & 0.5472 & 0.6207 & 0.5874 \\
\hline Gansu & 0.6380 & 0.6268 & 0.6103 & 0.6257 & 0.6463 & 0.6294 \\
\hline Qinghai & 0.7180 & 0.6807 & 0.6666 & 0.6800 & 0.6968 & 0.6884 \\
\hline Ningxia & 0.6279 & 0.6491 & 0.6070 & 0.6361 & 0.6574 & 0.6355 \\
\hline Xinjiang & 0.8660 & 0.8844 & 0.8965 & 0.9144 & 0.9452 & 0.9013 \\
\hline National average & 0.6578 & 0.6448 & 0.6660 & 0.6752 & 0.6896 & - \\
\hline
\end{tabular}


Table 4 reflects the basic trend of China's economic quality development: First, horizontally, provinces and regions such as Tianjin, Jilin, Jiangsu, Hainan and Xinjiang show a better level of quality development, while Beijing, Shanghai and Guangdong, where the network economy is better developed, show a mediocre level of quality development, which reflects the inconsistency of the two in some provinces and regions, and more deeply reflects that the network economy in quality development still needs Further deepen the synergy. Second, vertically, except for Inner Mongolia and Qinghai, almost all provinces have focused on the issue of high-quality development in their economic development after the 18th National Congress, and the quality of economic development in the five-year sample interval of this paper has been significantly improved. For example, Shanxi's economic quality development level increased from 0.5955 in 2013 to 0.6519 in 2014, and Jiangsu's economic quality development level increased from 0.5647 in 2014 to 0.966 in 2015 . Finally, nationally, the economic quality development level showed a slight regression in 2014 except for the rest of the years, which showed a significant increase in economic quality development. The effective improvement of the level of high-quality development requires the synergistic development of all levels of the economy, and it is more difficult to obtain a significant improvement in the short term, and can only be carried out in a practical and steady manner to build a modernized economic system.

\subsection{The Impact of Network Economic Development on the Quality Development of the Economy}

\subsubsection{PVAR Model Estimation}

The GMM method is used to estimate the PVAR model needs to determine the lag order of the model first, and in this paper, the Akaike information criterion (AIC) value, Bayesian information criterion (BIC) value and Hannan-Quinn information criterion (the optimal lag order is determined to be 1 based on the minimum selection criterion (Table 5). the estimation results of the PVAR model are shown in Table 6.

Table 5. Optimal lag order results

\begin{tabular}{|c|c|c|c|}
\hline lag & AIC & BIC & HQIC \\
\hline 1 & -4.62349 & -2.38952 & -3.74966 \\
\hline 2 & -3.529 & -.352951 & -2.51295 \\
\hline
\end{tabular}

Table 6. Estimation results of PVAR model

\begin{tabular}{|c|c|c|c|c|}
\hline \multirow{2}{*}{ Style } & \multicolumn{2}{|c|}{ h_dIE } & \multicolumn{2}{c|}{ h_dHQE } \\
\cline { 2 - 5 } & b_GMM & z & b_GMM & z \\
\hline L.h_dIE & -0.2073611 & -2.01 & 0.2106169 & 1.58 \\
\hline L.h_dHQE & -0.0458716 & -1.91 & -0.3618112 & -3.28 \\
\hline
\end{tabular}

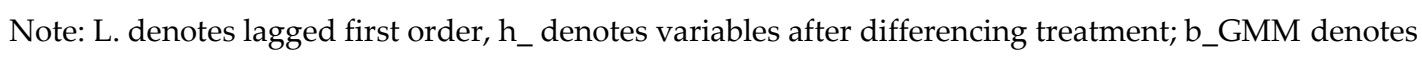
regression coefficients of explanatory variables. 


\subsubsection{Analysis of the Dynamic Effect of Network Economy and High-quality Economic Development}

In order to study the response mechanism of network economy development and highquality economic development more visually, the impulse response diagram is obtained (Figure 1).
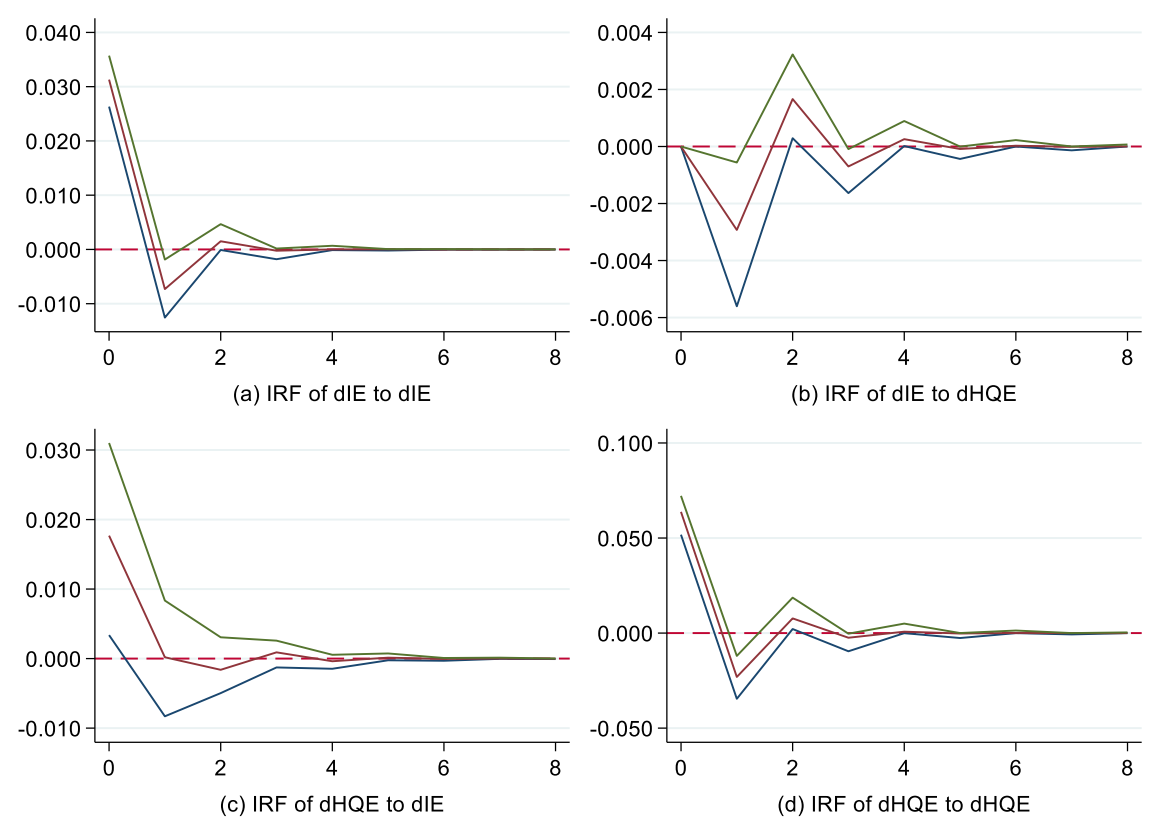

Figure 1. The dynamic relationship between the network economy and the high-quality economic development in the national region

First of all, from Figure 1(a) and Figure 1(d), it can be seen that both the network economy and the high-quality development of the economy can realize their own development inertia, that is, the good development foundation of the network economy can promote the better development of the future network economy of the country, and the positive promotion effect occurs immediately and can last for nearly four years. The high-quality development foundation of the economy can also continue to promote the high-quality development of the future economy of the country, not only the high quality the impulse can work immediately within a year and last longer than that of the network economy, with the impulse response function plotted at 5 years. As the most central measure of this paper, Figure 1(c) finds that the development of the network economy significantly contributes to the high-quality development of our economy. The figure shows that the positive pulse of the network economy is generated immediately and always positively on the high-quality development of our economy, and it shows a long-term driving effect that lasts for four years.

The results in Tables 3 and 4 show that although the overall effect of the network economy and the high-quality development of the economy is significant, there are significant regional differences. Although the previous literature focused mostly on the development differences between the eastern, central and western regions of China, the gap between the economic development of the south and north of China has been gradually expanding recently. From the GDP data of provinces and cities published in 2019, the total economic volume of the southern region occupies $65 \%$ of the country, while the total 
economic volume of the north occupies only 35\% of the country, and even the southwest region, which has the lowest economic level in the south, has developed very rapidly in recent years and has almost surpassed the northwest and northeast regions, strongly promoting the development of the entire southern region. On the contrary, the northeast and north China regions in the north have developed significantly slowly in recent years, obviously pulling down the development rate of the entire northern region. This phenomenon was also found by Du and Wu (2020), Wei et al. (2019) as well as Dai (2020). Therefore, this paper focuses more on the differential performance of network economy and economic quality development in the south and north of China, and also depicts Figures 2 and 3 for empirical analysis.
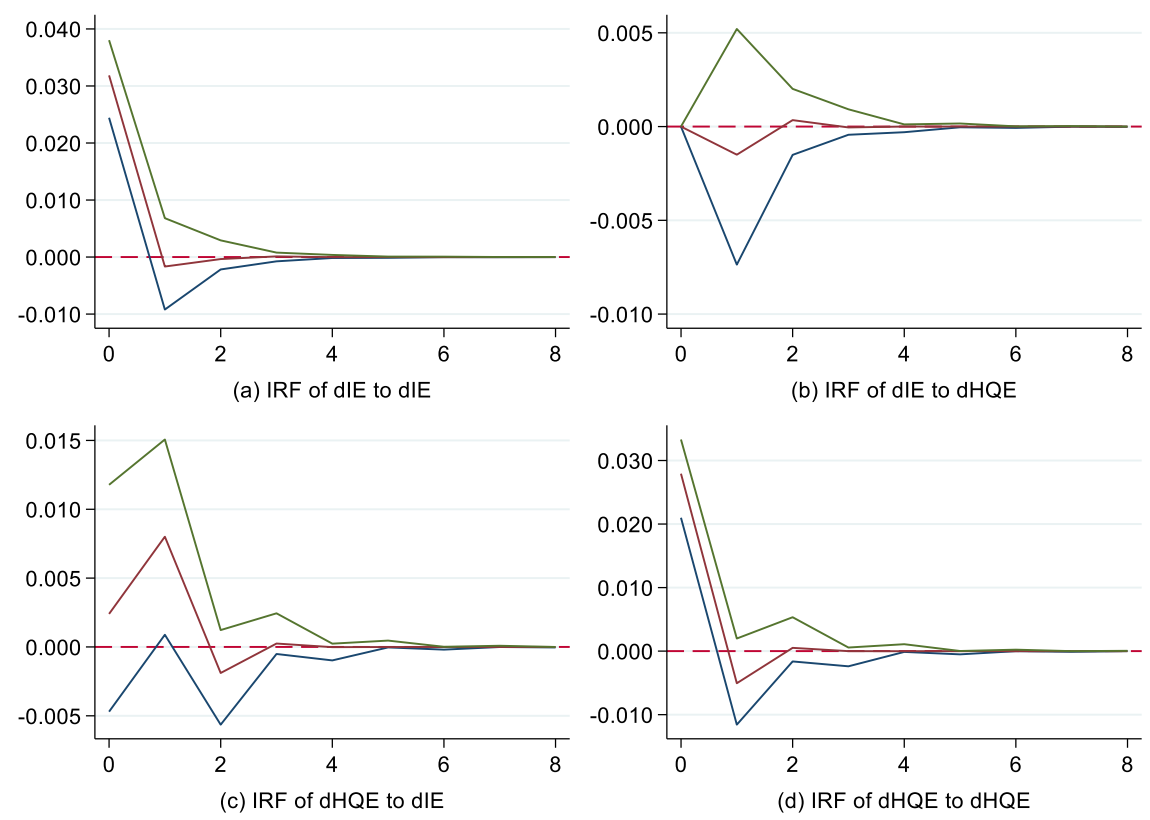

Figure 2. The dynamic relationship between the network economy and economic quality development in the northern region.

Comparing Figures 2 and 3, we can see that, first, similar to the national situation, the network economy and the quality development of the economy in both the South and the North can form a virtuous circle that promotes their respective development. There is no doubt that even though the current level of economic development in the North is lower than that in the South, both the network economy and the high-quality development of the economy are very important for both the South and the North, and both need to be developed in a focused manner. The difference is that the high-quality development of the South's economy is more significant for its own future high-quality development, with the maximum value of the impulse response function reaching 0.080 , while the North's is only 0.032 . It can be seen that the higher the quality development of the region, the more it contributes to its future high-quality development, which has formed a virtuous circle.

Second, the network economy has different mechanisms of action on the high-quality economic development of the northern and southern regions. Since the network economy is less developed in the northern provinces and regions than in the southern provinces and 

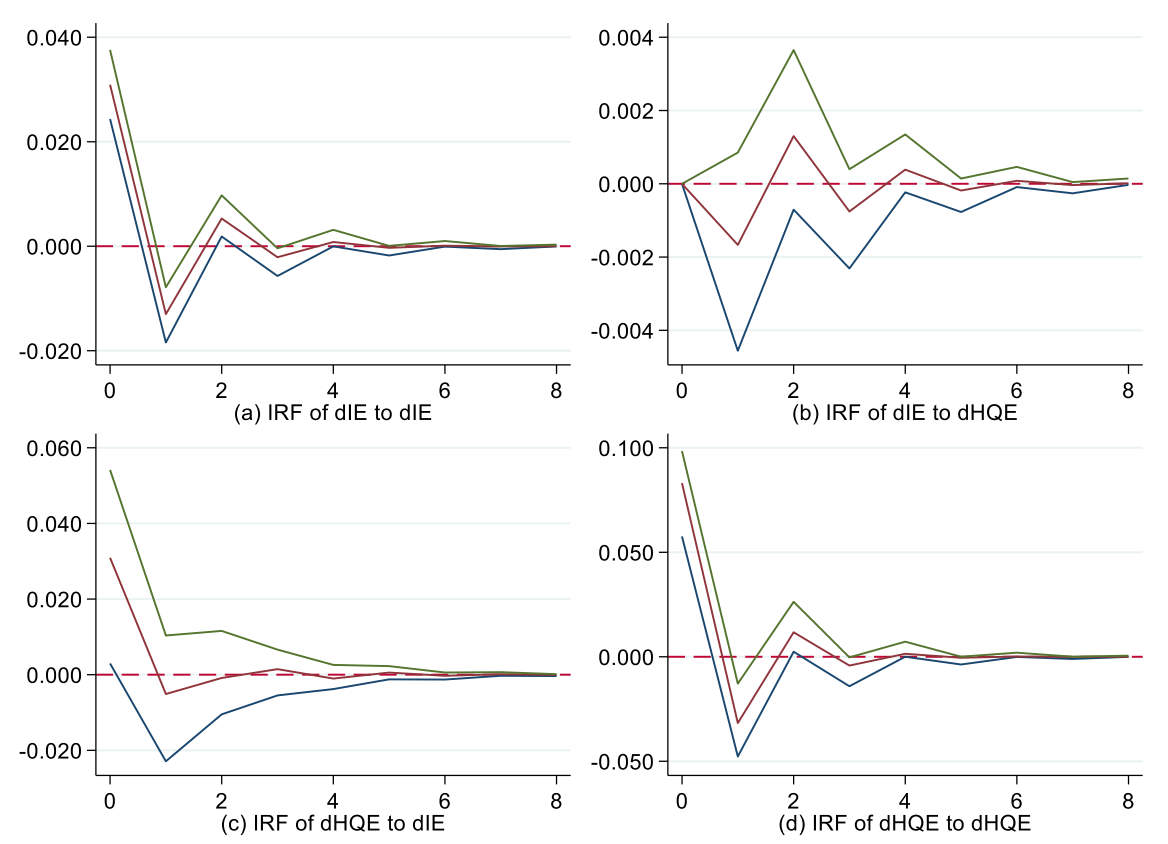

Figure 3. The dynamic relationship between network economy and economic quality development in the southern region

regions, the network economy has a slower onset and smaller effect in promoting highquality economic development. Figure 2(c) shows that the maximum effectiveness of the network economy is reached in the second year, and it is only 0.015 , while the network economy in the south has a larger and faster effect in promoting its economic quality development, within the same year when the network economy impulses occur and already has a driving effect of 0.04 on the economic quality development. Therefore, the different economic bases of the South and the North lead to the different role of the network economy in promoting the two.

Finally, at the level of high-quality economic development contributing to the development of the network economy, the South and the North show almost consistent similarity, i.e., the high-quality economic development is not very significantly affecting the development of the network economy. It can be seen that the difference in the impact on the network economy is not very significant for the time being under the condition that neither the high-quality development of the economy in the South nor the North is rapidly increasing.

\section{Conclusions}

Can the development of network economy effectively promote the high-quality development of China's economy? The study in this paper found that, firstly, the higher level of network economy development in economically developed and southern provinces and regions, among which Guangdong has the highest level of network economy development and has maintained the absolute leading position. Secondly, the quality of economic development in most provinces and regions in China has been significantly improved in recent years, with Tianjin, Jilin, Jiangsu, Hainan and Xinjiang showing better levels of high- 
quality development, while Beijing, Shanghai and Guangdong, where the network economy is better developed, from which it is reflected that the network economy needs to further deepen the synergy with high-quality development. Third, both the network economy and high-quality economic development can achieve their own development inertia, that is the good development foundation of the network economy can promote the better development of the network economy in the future, and the positive promotion effect happens immediately and can last for nearly four years. Fourth, the effect of high-quality economic development on the network economy takes a longer time and has a negative effect in the first year, which gradually changes to a positive effect from the second year onwards, so some aspects of the network economy cannot reach the requirements of high-quality development for the time being. Fifth, the development of the network economy has significantly contributed to the high-quality development of our economy in both the South and the North. The network economy can immediately have a positive impact on the high-quality development of China's economy, and it shows a long-term promotion effect that lasts for four years.

\section{References}

Ren, B. (2015). The path selection and reform orientation of improving the quality of China's economic growth under the new normal (in Chinese). Tianjin Social Science, 5, 84-90. https://doi.org/10.16240/j.cnki.10023976.2015.05.013

Jin, B. (2018). Economic research on "High Quality Development “(in Chinese). China's Industrial Economy, 4, 5-18. https://doi.org/10.19581/j.cnki.ciejournal.2018.04.001

Shi, B., \& Ren, B. (2018). Measurement and analysis of quality development of China's inter-provincial economy (in Chinese). Economic Issues, 4, 1-6. https://doi.org/10.16011/j.cnki.jjwt.2018.04.001

Ren, B. (2018). Target requirements and priorities of high-quality development in China (in Chinese). Red Flag Manuscript, 24, 21-23.

Li, M., \& Ren, B. (2018). Comprehensive evaluation of China's high-quality development in the new era and its path selection (in Chinese). Finance and Economics, 5, 26-40.

Fan, Z., Li, W., \& Wan, X. (2017). A preliminary study on the construction of the index system of Internet economic development level (in Chinese). Business Economic Research, 18, 187-189. https://doi.org/10.3969/j.issn.1002-5863.2017.18.062

Wu, Z., \& Liang, Q. (2020). Measurement, comparison and strategic path of China's high-quality economic development (in Chinese). Contemporary Finance and Economics, 4, 17-26. https://doi.org/10.13676/j.cnki.cn36-1030/f.2020.04.003

Du, Y., \& Wu, C. (2020). The widening economic gap between the north and the south of China: phenomenon, causes and countermeasures (in Chinese). Journal of Anhui University (Philosophy and Social Science Edition), 1, 148-156. https://doi.org/10.13796/j.cnki.1001-5019.2020.01.015

Wei, Y., Geng, D., \& Chen, T. (2019). Analysis of the north-south gap in China based on big data of science and technology (in Chinese). China Economic and Trade Journal, 16, 18-20. https://doi.org/ 10.3969/j.issn.10079777.2019.24.006

Dai, D. (2020). A study on the north-south economic development gap based on resource heterogeneity (in Chinese). Research on Technology Economics and Management, 6, 94-98. https://doi.org/10.3969/j.issn.1004292X.2020.01.016 